\title{
Effectiveness of Structured Teaching Programme Knowledge and Practice of Post Natal Mothers Regarding Essential New Born Care
}

\author{
Lavanyauriti \\ Dept of Nursing, \\ Himalaya University, \\ Arunachal Pradesh, \\ India
}

\author{
Manasa Godati \\ Dept of Nursing, \\ King Khalid University, \\ Abha, KSA,
}

\begin{abstract}
The present study was conducted to assess the level of knowledge and practice of postnatal mothers regarding essential newborn care. The research design for the study was one group pre-test post-test design. Asample of 200 postnatal mothers were selected by using purposive sampling technique at Bheemunipatnam selected community areas, vishakapatnam. The tools used for conducting the study were a set of demographic variables and Structured questionnarie. Structured teaching programme on essential new born care was conducted. The subjects were administered structured quesstionnarie on essential newborn care 30 days with pre and post assessment of structured questionnaire on essential newborn care. Data were analyzed with the help of descriptive and inferential statistics.
\end{abstract}

Among 200 postnatal mothers, majority 176(88\%), 164(82\%) had inadequate knowledge, 20 (10\%),32(16\%) had moderate knowledge and 4 (2\%),4 (2\%) had adequate knowledge the pre assessment of level of knowledge and practice on essential new born care. After the administration of structured teaching programme, majority 16(8\%), 20(10\%) had inadequate knowledge, 104(52\%),100 (50\%) had moderate knowledge and 80 (40\%),80 (40\%) had adequate knowledge in the post assessment of level of knowledge on essential new born care. It represents that of structured teaching programme was effective improved their knowledge on essential new born care among postnatal mothers.

There was no statistically significant association between post assessment of essential newborn care and the demographic variables such as age of the mother, education, religion, parity, type of delivery. There was statistically significant association between post assessment of essential level of knowledge on essential new born care and the demographic variables such as education and parity at $p<0.01$ level of significance.

\section{INTRODUCTION}

"A newborn baby is like the beginning of all things - Wonder, hope, a dream of possibilities."

The birth of a baby is one of life's most wondrous moments, babies have amazing abilities. Yet they are completely depended on others for feeding, warmth and comfort. Newborn is a continuum of the fetal life and very important transient time to adopt extra uterine life. The physical and mental wellbeing of every individual depends on the correct management of events in perinatal period. (Stephon W Elizabeth, 2004).

The newborn's body is the most super sensitive, delicate and susceptible from which can easily harmed if not taken care of. To ensure that the body has the best possible start in life there are critical aspects of newborn care, which all birth attendants and families should be aware of.

Environmental temperature should be maintained according to baby weight and age to avoid hypothermia. It is necessary to dry up the baby and wrap the baby with clothes make sure the baby head is covered (Dutta. P, 2008). 
Newborn or neonatal period include the time from birth to 28 days of life. This is the crucial period in laying the foundation of good health. At this time specific biological and psychological needs must be met to ensure the survival and health development of the child into a future adult. (Hocken Berry \& Wilson 2005).

The principles of essential newborn care is simple, requiring no expensive high technology equipment resuscitation, warmth to avoid hypothermia, early breast feeding, hygiene, support for the mother infant relationship and early treatment for low birth weight or sick infants (Hocken Berry and Wilson, 2005).

The first week of life is the most crucial period in the life of an infant. This is because the newborn has to adapt itself rapidly and successfully to an alien external environment. The risk of death is greatest during the first 24-48 hours after birth. Newborn morality is one of the most neglected health problems in the developing world, there are estimated 4 million neonatal deaths worldwide each year. Moreover, it is estimated to account for $40 \%$ of under five deaths and two-third of infant deaths. The proportion is generally higher in rural areas. According to World Health Report 2005, global neonatal mortalities rate is 36/1000, while in developing counties, the rate is 39/10006.(Belsey M 2000).

Poor perinatal and neonatal care is responsible for many deaths even during later childhood. They also account for mental retardation and other neurological handicaps of later life which are largely preventable. Improved neonatal care lead a better and intact infant survival, which will pave the way for better acceptance of small family norm. Mother plays a key role in identifying minor developmental deviations and early evidence of disease process because she is constantly and closely watching her baby. Participation of mother in the nursing care of baby infuses self confidence in her and reduces demands on nursing personnel. So she needs the basic knowledge and skills pertaining to child feeding, personal hygiene, immunization and other common problems in children.

India's current neonatal mortality is higher in rural areas at 49/1000 live births than in urban area at 27/1000 live births. Orissa have the highest neonatal mortality rate of 61/1000 live births. Karnataka, Uttar Pradesh, Madhya Pradesh, West Bengal, Punjab have the neonatal mortality rate of 54/1000, 53/1000, 51/1000, 31/1000, 29/1000 live births respectively. Kerala have the lowest neonatal mortality of 10/1000 live births respectively. It is necessary together to meet both national and the millennium development goal to reduce Neonatal Mortality rate by two thirds between 1990 and 2015. In India, Andhra Pradesh stands 6 place in neonatal mortality rate of 30/1000 live births. (WHO 2011).

The risk of neonatal mortality is more acute in rural areas where expert obstetric care is scarce, and the home environmental conditions in which the baby is born, are usually unsatisfactory. Roughly $60 \%$ of birth in less developed counties occurred at home, so parents need to be educated about what they can do to save their newborn lives. Families need to adapt better nutritional practices, including breastfeeding ; learn how to dry and warm their newborns; and better understand the danger signs of maternal and neonatal complication saving newborn lives depends on a broad based condition that include donors and international organizations that can provide policy focus and finding, governments that are willing to expand their commitment to national and local health care services, and NGOs and gross roots organizations that can work with communities to pass on information on saving newborns (Park. K, 2007).

The challenges of reducing neonatal mortality require solutions through research to inform programme innovation and action-oriented policies designed to improve newborn health. In all these above programmes, the mother plays a vital role. The community health nurse can educate the mothers regarding essential new born care and regarding antenatal care and postnatal care and regarding importance of institutional deliveries and through proper guidance and education regarding essential newborn care (Benny. W. Elizabeth, 2004).

Since mothers are the primary care takers of the newborns round the clock, it is the most important priority to improve their knowledge and competency. If a mother is educated, she can educate the entire family and the community as well.

\section{BACKGROUNG}

Newborn or neonatal period include the time from birth to 28 days of life. This is the crucial period in laying the foundation of good health. At this time specific biological and psychological needs must be met to ensure the survival and health development of the child into a future adult (Hocken Berry and Wilson, 2005). 
The major causes of neonatal deaths globally were estimated to be due to complications of prematurity, (28\%) sepsis, pneumonia (26\%), birth asphyxia, injuries (23\%), tetanus (7\%), congenital anomalies (7\%) and diarrhoea (3\%). A study done by Baqui, et.al., (2006) in rural Uttar Pradesh showed that out of 618 neonatal deaths, $32 \%$ deaths were on the day of birth, $50 \%$ occurred during the first 3 days of life and 71\% were during the first week of life. (Indian Institute of population 2010)

Care practices immediately after delivery play a major role in causing neonatal morbidities and mortalities. Essential newborn care practices were outlined to decrease the neonatal morbidity and mortalities. These practices include clean cord care, thermal care, and initiating breast feeding immediately after birth. The traditional practices like applying cow dung on the umbilical stump, oil instillation into nose, eyes also contribute to newborns risk of morbidity and mortality (Kesterten, A. J, 2010).

WHO reported that each year about 4 million newborns die before they are four weeks of life. Ninety eight percent of these deaths occurring in developing countries. Mortality rates are high in SubSaharan Africa and Asia. Two thirds of newborn deaths occur in the WHO regions of Africa (28\%) and East Asia (36\%). Neonatal mortality rate is now 6.5 times lower in the high income countries than other countries. The lifetime risk for a newborn baby is 1 in 5 in Africa compared with 1 in 125 in more developed countries.

India's current neonatal mortality is higher in rural areas at 49/1000 live births than in urban area at 27/1000 live births. Orissa have the highest neonatal mortality rate of 61/1000 live births. Karnataka, Uttar Pradesh, Madhya Pradesh, West Bengal, Punjab have the neonatal mortality rate of 54/1000, 53/1000, 51/1000, 31/1000, 29/1000 live births respectively. Kerala have the lowest neonatal mortality of $10 / 1000$ live births respectively. It is necessary together to meet both national and the millennium development goal to reduce Neonatal Mortality rate by two thirds between 1990 and 2015. In India, Andhra Pradesh stands 6 place in neonatal mortality rate of 30/1000 live births (WHO, 2011).

Still traditional practices of newborn care are seen among the mothers which are harmful to the newborn. Such as practice of pre-lacteal feeds like feeding sugar water or honey, castor oil, application of oil and powder to the umbilical cord, application of Kajal, instillation of oil in babies eye, ear and nose, baby being exposed and not covered well, lack of hygienic practices these are all contributes to the increased rate of neonatal morbidity and mortality.

Best practices of newborn care that includes maintenance of temperature, exclusive breastfeeding, skin care, eye care, cord care, prevention of infection, immunization (Mathur, N. B, 2010). Hence as a first step, the researcher felt the need for assessing the knowledge and practices of postnatal mothers with regard to essential newborn care at Bheemunipatnam, Vishakhapatnam.

\section{Methodology}

The research design for the study was one group pre-test post-test design. A sample of 200 postnaatal mothers were selected by using purposive sampling technique at Bheemunipatnam vishakapatnam. The tools used for conducting the study were a set of demographicvariables and Structured questionnarie. Structured teaching programme on essential new born care was conducted.The subjects were administered structured quesstionnarie on essential newborn care 30 days with pre and post assessment of structured questionnaire on essential newborn care.Data were analyzed with the help of descriptive and inferential statistics.

The tools used for the study were categorized into 2 sections.

The tool consists of three sections:

\section{Section-1 Description of Demographic variables}

$>$ It includes age of the mothers, educational status, occupation, income, religion, type of delivery, parity.

\section{Section-2: knowledge questionnaire}

$>$ It consists of 25 multiple choice questions to assess the knowledge regarding essential new born care. Each question has 4 options in which one option correct and other 3 options are wrong. Each correct answer carries one mark, wrong answer carries zero mark. 


\section{Section -3; Practice questionnaire}

$>$ It consists of 15 questions to assess the practice of essential new born care among postnatal mothers. Both positive and negative questions are formed based on observational check list.

\section{INTERPRETATION OF SCORES:}

The score was interpreted in the following manner

The scores were interpreted in the following manner.

A score bbetween $<50 \%$ Inadequate knowledge.

A score between (50-75\%) - Moderately adequate knowledge

A score between $>50 \%$ - Adequate knowledge

\section{EXPERIMENTS AND RESULTS}

- Among 200 postnatal mothers, majority 176(88\%), 164(82\%) had inadequate knowledge, 20 (10\%), 32 (16\%) had moderate knowledge and $4(2 \%), 4(2 \%)$ had adequate knowledge the pre assessment of level of knowledge and practice on essential new born care.

- After the administration of structured teaching programme. majority $16(8 \%), 20(10 \%)$ had inadequate knowledge, 104(52\%)100,(50\%) had moderate knowledge and 80 (40\%),80 (40\%) had adequate knowledge in the post assessment of level of knowledge and practice on essential new born care It represents that structured teaching programme was effective to improved knowledge and practice on essential newborn care among postnatal mothers.

- The present study also revealed that there was no statistically significant association between post assessment of level of knowledge and practice and the demographic variables such as age of postnatal mothers, religion, education, parity, type of delivery . There was statistically significant association between post assessment of essential level of knowledge on essential new born care and the demographic variables such as education and parity at $p<0.01$ level of significance.

Table1.Level of knowledge and practice in Pre-test

\begin{tabular}{|l|l|l|l|l|l|}
\hline \multicolumn{2}{|c|}{ Inadequate (<50\%) } & \multicolumn{2}{c|}{ Moderate (50\%-75\%) } & \multicolumn{2}{c|}{ Adequate (>50\%) } \\
\hline F & $\mathbf{\%}$ & F & $\mathbf{\%}$ & F & \% \\
\hline $\mathbf{1 7 6}$ & $\mathbf{8 8 \%}$ & $\mathbf{2 0}$ & $\mathbf{1 0 \%}$ & $\mathbf{4}$ & $\mathbf{2 \%}$ \\
\hline 164 & $\mathbf{8 2 \%}$ & $\mathbf{3 2}$ & $\mathbf{1 6 \%}$ & $\mathbf{4}$ & $\mathbf{2 \%}$ \\
\hline
\end{tabular}

The data presented in the Table -1 shows the level knowledge and practice among elderly postnatal mothers 176(88\%), 164(82\%) had inadequate knowledge, 20 (10\%), 32 (16\%) had moderate knowledge and $4(2 \%), 4(2 \%)$ had adequate knowledge the pre assessment of level of knowledge on essential new born care.

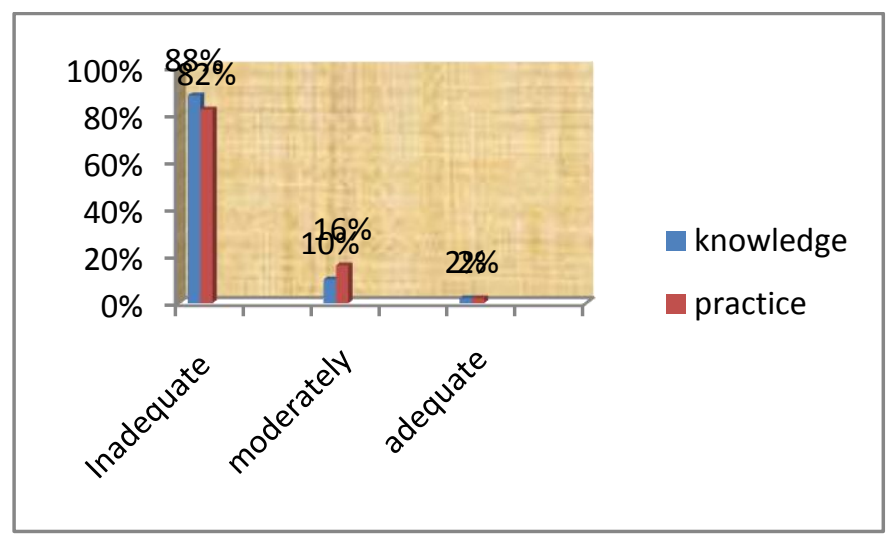

Table 2. Level of knowledge and practice in Post-Test

\begin{tabular}{|l|l|l|l|l|l|}
\hline \multicolumn{2}{|c|}{ Inadequate (<50\%) } & \multicolumn{2}{c|}{ Moderate (50\%-75\%) } & \multicolumn{2}{c|}{ Adequate (>50\%) } \\
\hline F & $\%$ & F & \% & F & \% \\
\hline 16 & $\mathbf{8 \%}$ & $\mathbf{1 0 4}$ & $\mathbf{5 2 \%}$ & $\mathbf{8 0}$ & $\mathbf{4 0 \%}$ \\
\hline 20 & $\mathbf{1 0 \%}$ & $\mathbf{1 0 0}$ & $\mathbf{5 0 \%}$ & $\mathbf{8 0}$ & $\mathbf{4 0 \%}$ \\
\hline
\end{tabular}


- The data presented in the Table 2 shows that the stress levels among elderly are majority 16(8\%),20(10\%) had inadequate knowledge, 104(52\%)100,(50\%) had moderate knowledge and 80 (40\%),80 (40\%) had adequate knowledge in the post assessment of level of knowledge and practice on essential new born care. It represents that structured teaching programme was effective to improved knowledge and practice on essential newborn care among postnatal mothers.

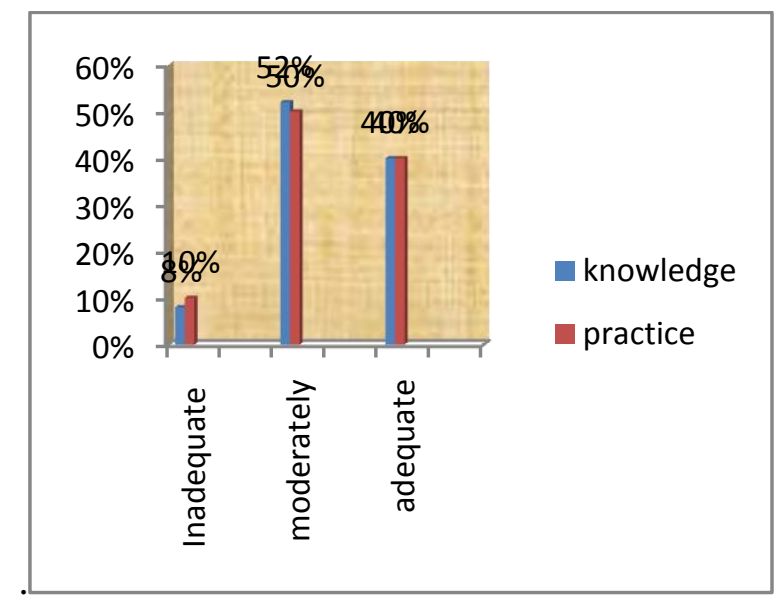

The mean score $12.72,5.62$ and standard deviation $2.303,1.723$ obtained in the pre- test and a mean score 19.06, 9.18and standard deviation 3.363,2.19 were obtained in the post test for the level of knowledge and practice among postnatal mothers showed that there was a increases in mean and standard deviation after the administration of structured teaching programme for postnatal mothers

\begin{tabular}{|l|l|l|l|}
\hline & Mean & Standard deviation & T value \\
\hline $\begin{array}{l}\text { Pre-test scores of level } \\
\text { knowledge and practice }\end{array}$ & $12.72,5.62$ & $2.303,1.723$ & 21.475, \\
\cline { 1 - 1 } $\begin{array}{l}\text { Post-test scores of level } \\
\text { knowledge and practice }\end{array}$ & $19.06,9.16$ & $3.363,2.19$ & 14.98 \\
\hline
\end{tabular}

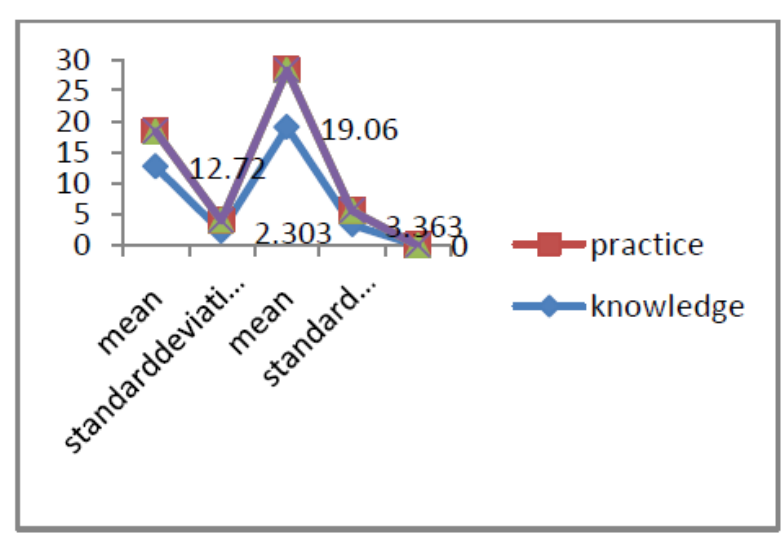

\section{Conclusion}

The research study was done to assess the effectiveness of structured teaching programme of knowledge and practice postnatal mothers regarding essential newborn care at bheemunipatnam Visakhapatnam.

About two hundred postnatal mothers were selected by purposive sampling technique. A structured questionnaire and observation checklist was used to assess the level of knowledge and level of knowledge on practice regarding essential new born care among postnatal mothers, before and after the structured teaching programme.

The first objective of the study was to assess the knowledge and knowledge on practices regarding essential new born care among postnatal mothers.

The pre-test was conducted by using the structured questionnaire, Table 3 revealed that out of 200 postnatal mother, $88 \%$ (176) had in adequate knowledge, 20\% (10) had moderately adequate 
knowledge, $4 \%$ (2) had adequate knowledge. Regarding the knowledge on practices related to essential newborn care, $88 \%$ (164) had inadequate knowledge, 32\% (16) had moderately adequate knowledge and 4\% (2) had adequate knowledge.

Post-test was conducted by using the same pre-test questionnaire; 7 days after the Health education to the postnatal mothers Table 4 revealed that out of 200 postnatal mothers $16 \%$ (8) had inadequate knowledge, 52\% (104) had moderately adequate knowledge and 40\% (80) had adequate knowledge on essential newborncare. Regarding knowledge on practices, $20 \%$ (10) had inadequate knowledge, $100 \%$ (50) had moderately adequate knowledge and $40 \%$ (80) had adequate knowledge on prevention of Burns and Scalds complications.

This study was supported by Vidhya. K (2011) conducted a pre-experimental study to assess the effectiveness of innovative teaching programme on new born care among postnatal mothers in Raja Muthaiah Hospital in North India. They had selected 30 postnatal mothers by convenient sampling technique. Data were collected by using a structured questionnaire. The pre-test results showed that $97 \%$ of the post natal mothers had inadequate knowledge on new born care and post test results showed that $70 \%$ of the postnatal mothers gained adequate knowledge on new born care and $30 \%$ of postnatal mothers gained moderately adequate knowledge on new born care. This study demonstrated that video teaching programme was effective in imparting knowledge to the postnatal mothers.

The second objective of the study was to evaluate the effectiveness of the Health education on essential new born care among post natal mothers. Table 5 revealed the effectiveness of the Health education. The paired ' $t$ ' test values showed that there was a significant improvement in the level of knowledge and level of knowledge on practices related to essential new born care at $\mathrm{P}<0.0001$ level.

The present study revealed improvement in the level of knowledge and level of knowledge on practices related to essential new born care after administering the health education programme. It was proved that direct education can lead to increase in the level of knowledge and level of knowledge on practices related to essential new born care.

The third objective was to associate the relationship between selected demographic variables and the level of knowledge and knowledge on practices among postnatal mothers related to essential new born care.

Table 6 represents in the post test, the association between demographic variables with level of knowledge on essential new born care. The association between the level of knowledge education and parity was significant at $\mathrm{p}<0.05$. Table 7 represents in the post test, the association between level of knowledge on practice age, education and parity was significant at $\mathrm{p}<0.05$

Still some of the demographic variables are not significant with the mother's knowledge. Irrespective of demographic variables, the post natal mothers improved their knowledge after receiving structured teaching programme. Hence, direct education has a bearing and can bring about improvement of their knowledge and change in a desirable behaviour.

\section{REFERENCES}

[1] Stephon W.Elizabath R.Research priorities to improve global forum for health research. Mexico 2004.

[2] Parul Dutta . Paediatric Nursing. ( $8^{\text {th }}$ edition). New delhi: Jaypee brothers publishers $2008 ; 110-$ 113.

[3] Hocken berry and Willson, Wong's Nursing Care of Infants and Children. ( $8^{\text {th }}$ edition.). New Delhi: Elservier publishers 2005: 200-204.

[4] Belsey, M.(2000), global overview of Newborn health, summary of oral report to Director General of WHO Executive board.

[5] World health organization. Essential Newborn Care (2011). A Report of technical working Group. Geneva.

[6] Park .k preventive and social medicine, $22^{\text {nd }}$ edition,Jabalpur,Bhannot,2007 451-455. 


\section{AUTHORS' BIOGRAPHY}

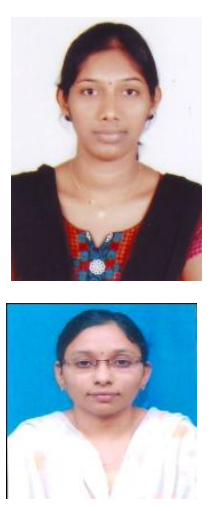

Manasa Godati, persuing phD degree, received M.Sc Nursing degree in Mental Health (Psychiatric) Nursing specialty from SVIMS University, AP, and India. She has 5 years of teaching experience. Her area of interest in research is Psychiatric Nursing.

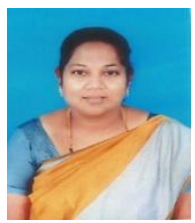

Lavanya Uriti, Student of PHD (Nursing) under Himalaya University, received M.Sc Nursing degree in child health nursing Nursing specialty from SVIMS University, AP, and India. She has 5 years of teaching experience. Her area of interest in research is child health Nursing.

Dr. Rajina Rani, Principal, Rass Academy college of Nursing, Poovanthi, Sivagangi (dt), Tamilnadu. 